\title{
Anticancer therapy within the last 30 days of life in a regional cancer centre
}

M Nguyen, ${ }^{1}$ E Shum, ${ }^{1}$ S Ng Ying Kin, ${ }^{1}$ A Wann, ${ }^{1}$ B Tamjid, ${ }^{1,2}$ J Torres ${ }^{1,2}$

Department of Medical Oncology, Goulburn Valley Health, Victoria Australia

RHAC, the University of Melbourne, Shepparton, Victoria, Australia

\section{BACKGROUND}

The rapid development of anticancer treatments has resulted in a myriad of therapeutic options. Within this context of treatment temptation, systemic anticancer treatment within the last 30 days of life has become a key quality of care indicator. ${ }^{1}$

\begin{tabular}{|c|c|c|c|c|c|c|}
\hline & \multicolumn{2}{|c|}{ All patients } & \multicolumn{2}{|c|}{$\begin{array}{l}\text { Treatment within } 30 \\
\text { days }\end{array}$} & \multicolumn{2}{|c|}{$\begin{array}{l}\text { Treatment not within } \\
30 \text { days }\end{array}$} \\
\hline & Number & $\%$ & Number & $\%$ & Number & $\%$ \\
\hline & 221 & & 70 & $32 \%$ & 151 & $68 \%$ \\
\hline \multicolumn{7}{|l|}{ Sex } \\
\hline Male & 127 & $57 \%$ & 40 & $57 \%$ & 87 & $58 \%$ \\
\hline Female & 94 & $43 \%$ & 30 & $43 \%$ & 64 & $42 \%$ \\
\hline \multicolumn{7}{|l|}{ Discipline } \\
\hline Oncology & 202 & $91 \%$ & 62 & $31 \%$ & 140 & $69 \%$ \\
\hline Haematology & 19 & $9 \%$ & 8 & $42 \%$ & 11 & $58 \%$ \\
\hline Average age & 71 & & 70 & & 71 & \\
\hline \multicolumn{7}{|l|}{$\begin{array}{l}\text { Performance } \\
\text { status }\end{array}$} \\
\hline$E C O G 0$ or 1 & 50 & $23 \%$ & 22 & $31 \%$ & 28 & $19 \%$ \\
\hline$E C O G 2$ & 103 & $47 \%$ & 24 & $34 \%$ & 79 & $52 \%$ \\
\hline$E C O G 3$ or 4 & 68 & $31 \%$ & 24 & $34 \%$ & 44 & $29 \%$ \\
\hline \multicolumn{7}{|l|}{$\begin{array}{c}\text { Line of } \\
\text { treatment }\end{array}$} \\
\hline First line & 106 & $48 \%$ & 35 & $50 \%$ & 71 & $47 \%$ \\
\hline Second line & 68 & $31 \%$ & 21 & $30 \%$ & 47 & $31 \%$ \\
\hline $\begin{array}{l}\text { Third line or } \\
\text { greater }\end{array}$ & 47 & $21 \%$ & 14 & $20 \%$ & 33 & $22 \%$ \\
\hline \multicolumn{7}{|l|}{$\begin{array}{l}\text { Distance from } \\
\text { centre }\end{array}$} \\
\hline $0-50 \mathrm{Km}$ & 171 & $77 \%$ & 52 & $74 \%$ & 119 & $79 \%$ \\
\hline $50-100 \mathrm{Km}$ & 48 & $22 \%$ & 17 & $24 \%$ & 31 & $21 \%$ \\
\hline $100+\mathrm{Km}$ & 2 & $1 \%$ & 1 & $1 \%$ & 1 & $1 \%$ \\
\hline
\end{tabular}

\section{METHODS}

Retrospective review of medical records of all patients treated at the Peter Copulos Cancer Centre with:

- Deaths between 1 October 2015 and 15 March 2018

- Received any anticancer therapy including chemotherapy, immunotherapy, targeted therapy, monoclonal antibodies, endocrine therapy and hormonal treatment

\section{RESULTS}

- 70 of 221 deaths (32\%) occurred in patients who had received anticancer therapy within the last 30 days of life.

- 40 of $153(26 \%)$ died within 30 days of chemotherapy treatment.

- The majority (94\%) were treated with palliative intent.

- Aggressive treatment tended to occur in those with better performance status and haematology patients.

- Rates of treatment did not differ significantly with regards to sex, line of treatment or distance from treatment centre.

- Palliative care referral rates were lower in those who received treatment within 30 days of death.

\section{Palliative Intent and Referral}

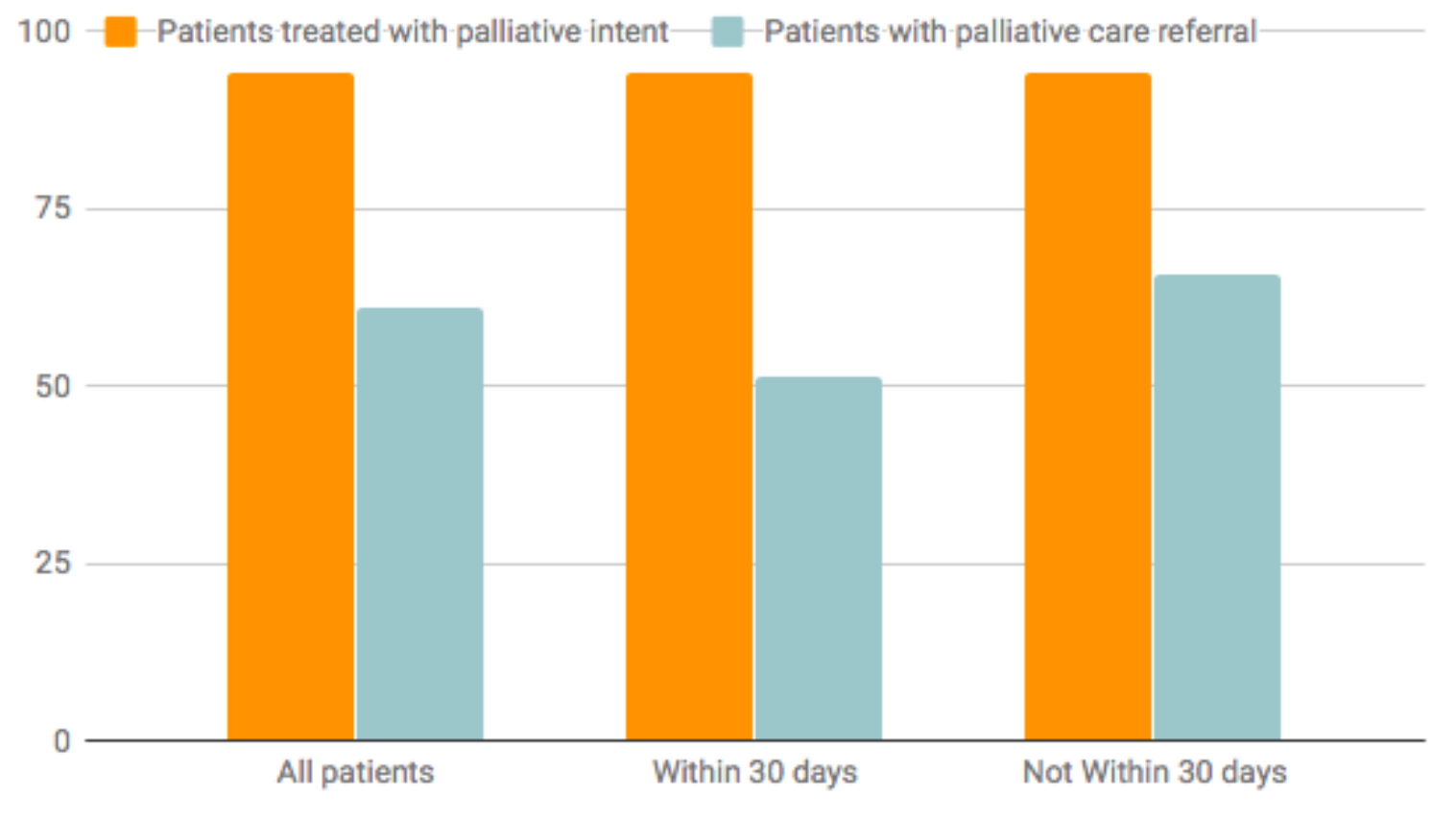

\section{Number of patients by tumour type}

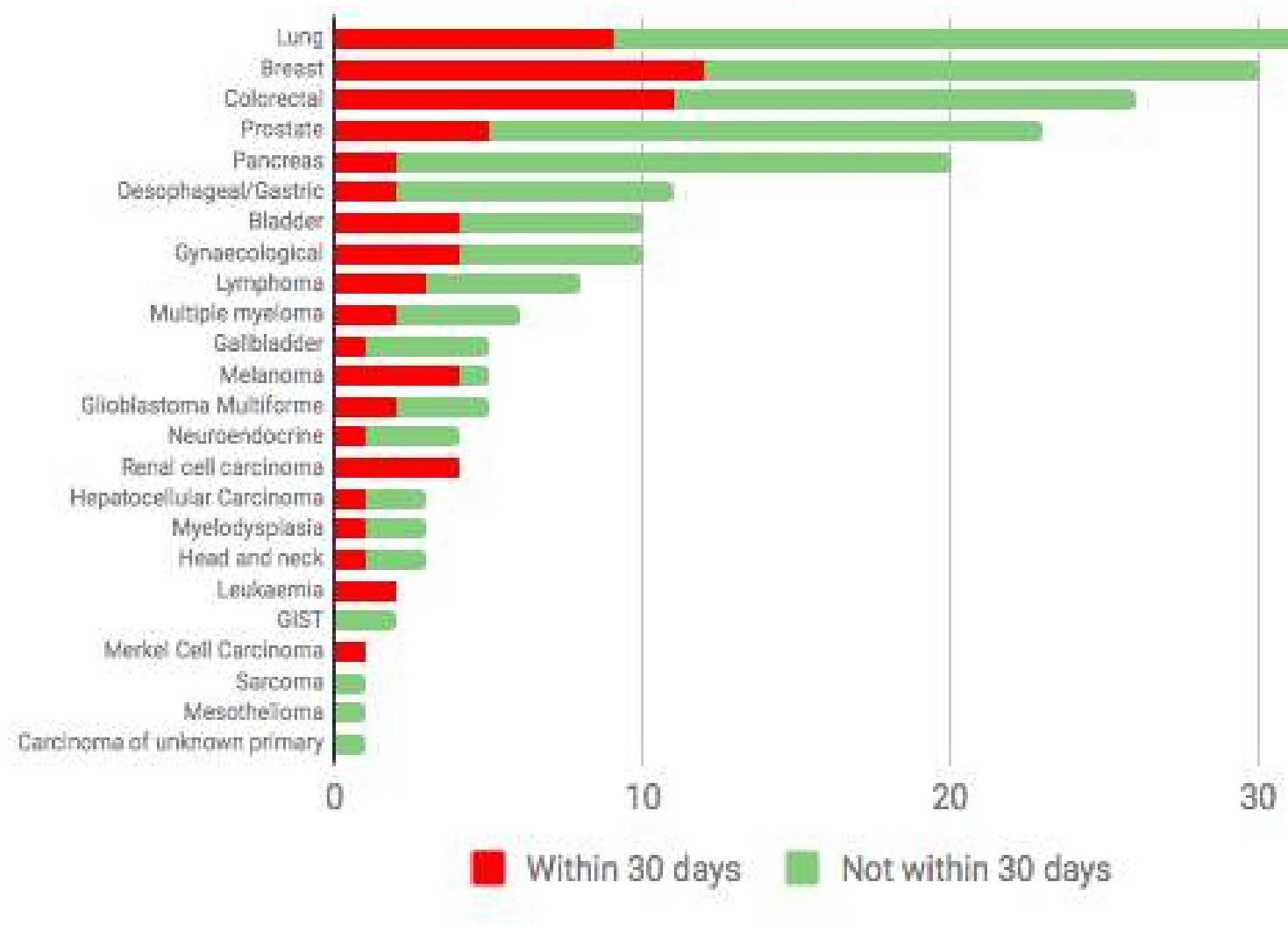

DISCUSSION

A direct comparison with published findings from other institutions in Australia is difficult as other investigators have used different population definitions, inclusion criteria and we have included a wider range of anticancer treatments - cytotoxic chemotherapy, immunotherapy, targeted therapy, monoclonal antibodies, endocrine and hormonal treatments.

Rates of mortality within 30 days of systemic anticancer treatment amongst all patients receiving treatment range from $3.4 \%$ to $18 \%{ }^{2}$ Wein et al. ${ }^{3}$ reported $26 \%$ of patients who died had received anticancer treatment, including endocrine and targeted therapy, within the last 30 days of life. Kao reports $18 \%$ of patients who died had received cytotoxic chemotherapy within the last 30 days of life. ${ }^{4}$

\section{Treatment Type}

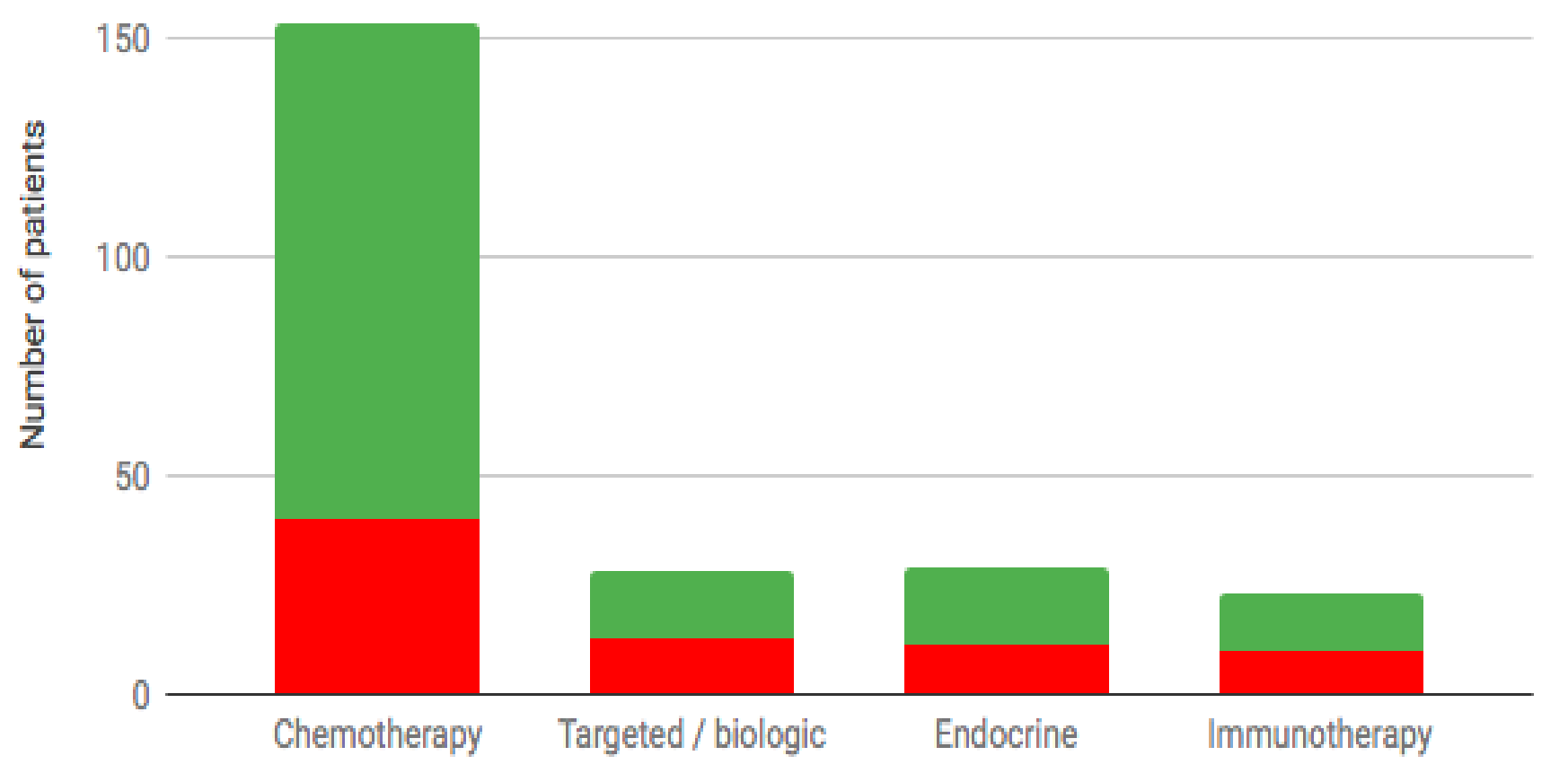

The majority of patients were referred to palliative care services. Both the American Society of Clinical Oncology and the European Society of Medical Oncology have formalised the early involvement of palliative care services for patients with advanced cancer concurrently with active anticancer treatment as a key recommendation of clinical guidelines. $^{56}$

\section{CONCLUSION}

Our audit of all deaths found that almost a third of patients had received systemic anticancer therapy within the last 30 days of life. This emphasises the inherent difficulties in accurate disease prognostication, identifying when patients enter the end of life period and the difficult decision to continue or cease anticancer treatment. 